\title{
The Role of microRNAs in Embryonic and Induced Pluripotency
}

\author{
Beh-Pajooh A ${ }^{1}$, Cantz T ${ }^{1,2}$
}

\begin{abstract}
Research on stem cells is one of the fastest growing areas of regenerative medicine that paves the way for a comprehensive solution to cell therapy. Today, stem cells are precious assets for generating different types of cells derived from either natural embryonic stem (ES) cells or induced pluripotent stem (iPS) cells. The iPS technology can revolutionize the future of clinics by offering personalized medicine, which will provide the future treatment for curing untreatable diseases. Although iPS cell therapy is now at its infancy, promising research has motivated scientists to pursue this therapeutic approach. In this article, we provide information regarding similarities and differences between ES and iPS cells, and focus on the non-integrating methods of iPS generation via RNA molecules, especially microRNAs with an emphasis on the elucidation of their role and importance in pluripotency.
\end{abstract}

Key Words: Pluripotency, ES cells, iPS cells, microRNA, Precursor microRNA

\section{Embryo-Derived and Induced Pluripotent Stem Cells: Similarities and Differences}

The initial approach of isolating human pluripotent stem cells derived from the inner cell mass of blastocysts involved the destruction of a human embryos and raised severe ethical concerns. One could argue that cryo-conserved surplus of in vitro fertilization (IVF)-derived embryos will never have the actual chance to develop into a born human and, thus, may be used for the generation of human embryonic stem (ES) cells, if they were donated voluntarily and with prior consent. On the other hand, it is argued that one should address the full dignity to all human beings, which includes embryos that have the potential to develop into a born human being. More than 15 years after these issues were intensively debated amongst philosophers and natural scientists, it is interesting to see that the very first set of isolated human ES cell lines, such as H1 (male) ES cells and H9 (female) ES cells ${ }^{[1]}$ are still used in the majority of labs that work with human embryonic stem cells and that not every lab attempted to generate their own stock of human ES cell lines.

Induced pluripotent stem (iPS) cells are regarded as an alternative to ES cells to overcome those ethical problems. iPS cells like ES cells are pluripotent and can self renew and differentiate into all three primary germ layers and form teratomas and chimeric mice $^{[2,3]}$. The first human iPS cell line was generated by transduction of retroviral vectors encoding pluripotency associated factors of OCT4, SOX2, KLF4 and c-MYC (OSKM) into human adult dermal fibroblasts with an efficiency of reprogramming of about $0.02 \%{ }^{[4]}$ or by lentiviral transfection of OCT4, SOX2, NANOG, LIN28 (OSNL) with similar low efficiency ${ }^{[5]}$.
In a study comparing transcriptional profiles of iPS and ES cellderived cardiomyocytes, the iPS-derived isolated beating clusters demonstrated that they only differ in $1.9 \%$ of transcriptional profiles compare to human cardiomyocytes derived from ES cells and showed the same functional and physiological efficiency. However, the iPS-derived beating clusters shared some genetic and epigenetic features with undifferentiated iPS cells ${ }^{[6]}$. In another study, neuronal cells derived from iPS and human ES cells were compared and the results showed high functional and transcriptional similarity; however, with lower efficiency and high variability compared to ES cell-derived neuronal cells ${ }^{[7]}$. It was shown that human hepatocytes derived from iPS cells which were generated from adult fibroblasts by OCT4, SOX2, KLF4 (OSK) plus Utf1 lentiviral transduction could generate efficient hepatocytes like that of human ES cellderived hepatocytes ${ }^{[8]}$ and retrovirally OSKM generated iPS cellderived hepatocytes that were indistinguishable from human ES cells and iPS cells could efficiently differentiate into endoderm derived cells and provide a suitable way to study liver disease specific iPS cells ${ }^{[9]}$.

The first study that investigated DNA methylation patterns in the whole genome of human iPS cells showed a high similarity in global patterns at CG context and non-CG DNA methylation levels and distribution to human ES cells; however, there were huge mega base size regions that had differences in CG methylation and histone modification with aberrant non-CG methylation regions close to centromeres and telomeres, showing high variability and incomplete reprogramming of iPS cells ${ }^{[10]}$. In another study, it was demonstrated that the method of reprogramming underlines a difference on genome wide methylation pattern, where it was shown that human "NT-ES" cells derived by somatic cell nuclear transfer (SCNT) from human fetal dermal fibroblasts and IVF-derived 
ES cells, have similar methylation and transcription profiles. Also, genetically matched iPS cells and NT-ES cells have similar levels of de novo copy number variations as well. However, iPS cells generated from human fetal dermal fibroblasts with Yamanaka transcription factors via retrovirus/Sendai virus have partially inherited DNA methylation patterns inherited from their parental somatic fibroblasts, indicating incomplete epigenetic reprogramming ${ }^{[11]}$. On the contrary, more recent studies comparing syngeneic human ES- and iPS cell lines could not demonstrate significant differences at the global gene expression or methylation level ${ }^{[12,13]}$.

Although iPS cells are morphologically and functionally similar to ES cells, it has been discussed that they may harbor distinct differences in the expression of some genes and microRNAs that is mainly due to different strengths of promoter binding by reprogramming factors ${ }^{[14]}$. There are highly expressed microRNAs in ES or iPS cells, like miR302 cluster and miR-17-92 cluster and members of chromosome 19 microRNA cluster (C19MC). Hierarchical clustering analyses of microRNA profiles of human and mouse ES and iPS cells showed highly similar expression patterns with minor microRNA expression profile differences. However, there are some microRNAs including members of $\mathrm{C} 19 \mathrm{MC}$ that are expressed more in human iPS cells rather than ES cells, but both share a distinct microRNA profile of miR-187, 299-3p, 499-5p, 628-5p and miR-888 expression which specifically characterizes human ES and iPS cells from other cells. let-7 (let-7-b,e,f,g) and miR-30 (miR-30-a-e) families are expressed stronger in murine iPS cells compare to ES cells, but they share a distinct microRNA expression profile of miR-133b, 200a, 23a, and $743 b-5 p$, which distinguishes mouse ES and iPS from other cell types $^{[15]}$.

\section{Involvement of microRNAs in the Generation of iPS Cells}

There are numerous approaches for generation of iPS cells, but here we focus on RNA molecules, which do not integrate into the host's genome and may be considered as safer approach compared to other methods. Treatment of cells with synthetic mRNAs has many advantages including lack of genomic integration and easy delivery into the cells and quick translation, but its disadvantages include requirement to multiple rounds of transfection due to the short life span of mRNA and eliciting some immunogenic response, which could be reduced by phosphatase treatments. It has been demonstrated that electroporation of mRNAs encoding for five factors of Oct4, Sox2, c-Myc, Klf4 and SV40 large T antigen into human fibroblasts could induce endogenous Oct4, Nanog, Dnmt3b, Rex1 and Sall4 expression comparable to human ES cells ${ }^{[16]}$. Delivery of synthetic mRNAs by cationic lipid vehicles into human fibroblasts encoding five factors of Klf4, c-Myc, Oct4, Sox 2 and Lin28 shows an increased efficiency of reprogramming of at least 2\% in media without Y27632 ROCK inhibitor, generating RNA-induced pluripotent stem cells (RiPSCs) and rising up to $4.4 \%$ in $5 \% \mathrm{O}_{2}$ concentration with emerging colonies within about 2 weeks ${ }^{[17]}$.

Interestingly, LIN28 is strongly associated with stem cell pluripotency and binds to the let-7 microRNA transcript family of let-7 PrimicroRNA, let-7 pre-microRNA and let-7 microRNA to promote stem cell self-renewal, indicating the importance of microRNAs in pluripotency ${ }^{[18]}$. Clearly, microRNAs as non-coding RNAs with 19-25 nucleotides have an inevitable role in the network of pluripotency by modulating multiple targets and it was even speculated that microRNAs have the potential to generate iPS cells solely without the need for ectopic expression of pluripotency related factors though with low efficiency of reprogramming. It has been reported that retroviral delivery of pre-miR-302 cluster into human cancer cell lines could reprogram them into microRNA- induced pluripotent stem
(mirPS) cells, exhibiting high similarity in genome-wide gene expression patterns to human $\mathrm{H} 1$ and $\mathrm{H} 9 \mathrm{ES}$ cells ${ }^{[19]}$. In a similar study, it was demonstrated that normal human hair follicles could be reprogramed into human iPS cells via electroporation of doxycycline inducible pTet-On-tTS vectors expressing pre-microRNA members of miR-302 cluster including pre-miR-302a, 302b, 302c and 302d. These miR-302 family members target epigenetic regulators such as the lysine-specific histone demethylases of AOF and AOF2, or methyl-CpG binding proteins of MECP1-p66 and MECP2 and promote global demethylation during reprogramming of somatic cells into mirPS cells by decreasing DNA methyltransferase 1 (DNMT1). Although in these two studies the efficiency of reprogramming was not reported, it underlines that microRNAs may independently generate iPS cells from human cells ${ }^{[20]}$ or are at least important modulators of the complex reprogramming process (Figure 1). It has been described that four rounds of transfections in 48 hours intervals comprising of miR-200c, the miR-302 family and the miR-369 family (miR-302b/c/a/d/367) into mouse adult adipose stromal cells, successfully generated microRNA induced iPS cells at a rather low efficiency $(0.03 \%)$. When the same protocol was applied to human adipose stem cells and human dermal fibroblasts, iPS cell generation was described to occur at an efficiency of $0.002 \%$ within two weeks ${ }^{[21]}$.

\section{Importance of Pluripotency Related microRNAs}

Over $60 \%$ of human encoding genes are controlled by microRNAs ${ }^{[22]}$ and, thus, one could clearly state that the identity of a cell is not only characterized by its gene expression signature but also by the abundance of specific microRNAs ${ }^{[23]}$. Initial reports estimated about 250 mRNAs to be the target of the seed sequence "AAGUGC" of naturally expressed microRNAs ${ }^{[24]}$ showing the importance of this
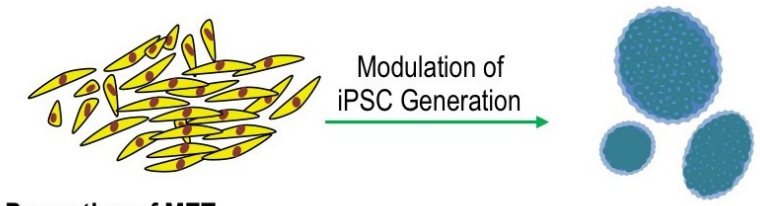

Promotion of MET

miR-302-367

miR-200

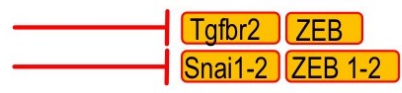

Epigenetic Modulation miR-302-367

miR-29b

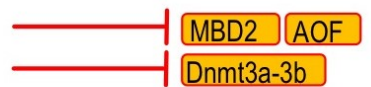

Repressing MicroRNAs
miR-199a-5p
miR-199a-3p
miR-132 \& miR-212
miR-145

Predicted repressing MicroRNAs miR-296

miR-470

miR-766
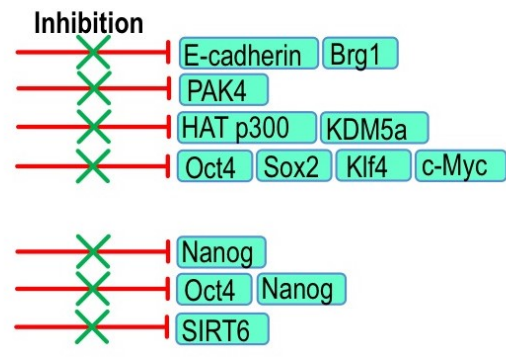

deactivate / target
$\times$ de-repress / activate

pluripotency enhancing factors pluripotency suppressing factors

Figure 1: Roles of microRNAs in reprogramming of somatic cells into iPS cells

The main mechanism of reprogramming includes transition from the mesenchymal to epithelial state (MET) and global epigenetic remodelling. Thus, inhibition of genes that favour the mesenchymal state would enhance reprogramming. Also, de-repression of microRNAs that target reprogramming favouring genes supports the generation of iPS cells from somatic cells. 
group of microRNAs which are known as ES cell-specific cell cycleregulating (ESCC) microRNAs ${ }^{[25]}$. Pluripotency related microRNAs can be divided into two groups of dominantly expressed endogenous microRNAs in stem cells with the above mentioned seed sequence and the second group of microRNAs which have an enhancing effect on stemness or reprogramming that may or may not contain that particular seed sequence and may or may not be expressed by stem cells naturally (Figure 2). Regarding all microRNAs which are expressed in embryonic stem cells, microRNAs with the seed sequence of "AAGUGC" on position 2-7 are the most abundant and important microRNAs related to pluripotency in human and mouse and include two microRNA families including the broadly conserved miR-302/367 cluster (miR-302a, miR-302b, miR-302c, miR-302d, miR-367) and a less conserved microRNA group, which in mouse is referred to as the miR-290-295 cluster (miR-290, miR-291a-3p, miR291b, miR-292, miR-294, miR-295, miR-293) and its corresponding clusters in humans as the miR-371-373 cluster (comprised of human miR-371, miR-372, miR-373)[26].

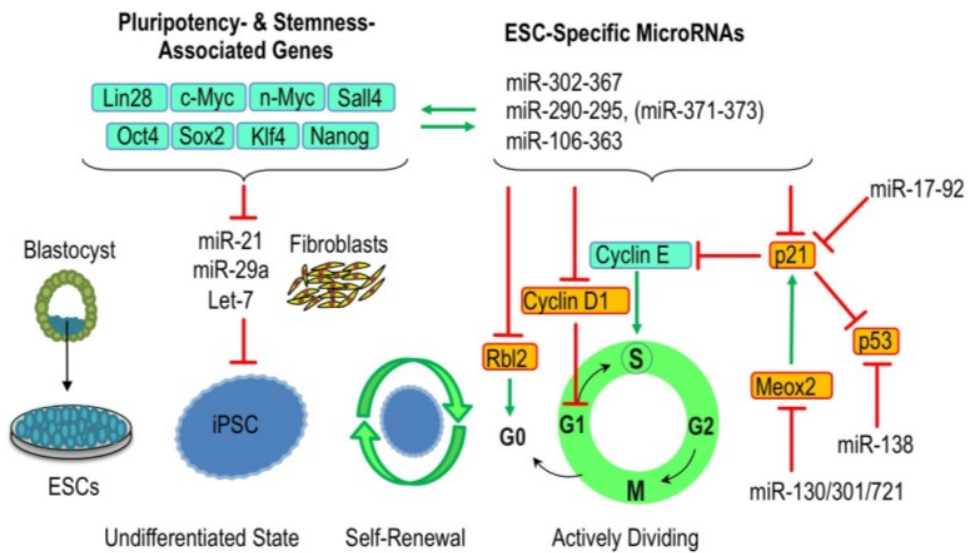

Figure 2: microRNAs involved in control of pluripotency and self-renewal

Stemness related genes and microRNAs boost the network of pluripotency by targeting key cell cycle players and by supressing somatic cell- (e.g. fibroblast-) specific microRNAs.

Likewise, the primate ES cell-specific microRNA, hsa-miR-519a also shares the "AAGUGC" seed sequence and the functionality with the ESCC microRNAs ${ }^{[27]}$. Besides the above-mentioned microRNA clusters, which comprise of the dominant microRNAs expressed in embryonic stem cells, other ES cell-enriched microRNAs also have the seed sequence of "AAGUGC" on position 3-8 (e.g. miR-106a, miR-106b, miR-20b, miR-93, miR-17, miR-20a, hsa-miR-519a). Interestingly, another set of microRNAs contain the seed sequence of "AUUGCAC" of miR-367 on position 2-8 (miR-25, miR-32, miR92a-1, miR-92a-2, miR-92b, miR-363) and enhance the maintenance of pluripotency or get induced early during reprogramming $[28,29]$. Some other microRNAs share the same seed sequence like of the miR-17-92 cluster, but they are also expressed in B cell lymphoma and lung cancer cells ${ }^{[30]}$, or miR-520c and miR-373 which are expressed in human epithelial tumors ${ }^{[31]}$. The importance of microRNAs is exhibited as independent alternatives to reprogramming factors where it has been demonstrated that miR-302367 cluster can replace the Klf4 and c-Myc in the OSKM cocktail when administered as three plasmids of Oct4, Sox2, miR302-367 with cationized Pleurotus eryngii polysaccharide nanoparticles during reprogramming human umbilical cord mesenchymal stem cells into iPS cells with higher efficiency $(0.044 \%)$ and safety ${ }^{[32]}$. It has also been demonstrated that inclusion of miR-291-3p, miR-294, and miR295 to the OSK cocktail but not OSKM, could enhance the reprogramming of MEFs into iPS cells, suggesting that these microRNAs can functionally substitute c-Myc. Furthermore, it was reported that inclusion of miR-294 had the highest positive effect during iPS cell generation by raising the efficiency of reprogramming from $0.01-0.05 \%$ in OSK alone to $0.1-0.3 \%{ }^{[33]}$. In another study higher reprogramming efficiencies were obtained when miR-302 was included in the OSKM cocktail during reprogramming human adipose-derived stem cells into iPS cells, demonstrating the repressing effect of miR-302 on nuclear receptor subfamily 2, group $\mathrm{F}$, member 2 (NR2F2) which in turn directly inhibits the activity of the OCT4 promoter $^{[34]}$.

Lentiviral transduction of OSKM along miR-302/367 cluster into mouse embryonic fibroblasts (MEFs) harboring an Oct4-GFP reporter cassette in the presence of HDAC Inhibitor valproic acid (VPA) could give rise to more than double the number of GFP positive colonies compared to OSKM alone, within 6-8 days post transduction. The same approach (lentiviral delivery of OSKM and miR302/367) was applied to human foreskin and dermal fibroblasts without VPA. Here, the number of observed colonies around days 12-14 post transduction was doubled in comparison to OSKM alone, indicating the importance of this microRNA cluster in reprogramming human fibroblasts into iPS cells ${ }^{[35]}$. These data was further confirmed in a study screening a library of 379 premicroRNAs, which were transfected into MEFs during initial phase of reprogramming into iPS cells ${ }^{[29]}$, where this microRNA family was amongst the candidates that strongly enhanced the reprogramming efficiency.

\section{Mechanism of Action}

It has been shown that reprogramming factors of Oct 4 and Sox 2 bind to promoter regions of the miR-302 cluster and are required for its expression in human embryonic stem cells and miR-302 members themselves target the cell cycle regulator Cyclin D1/Cdk4 in human embryonic stem cells and thus prevent the cells from passing from G1 phase to the S phase, which at least partly explains the short G1 phase and prolonged S phase in ES cells compared to differentiated cells $^{[36]}$, (Figure 2). In murine ES cells, the miR-290/295 cluster targets the Cyclin-dependent kinase inhibitor 1 (Cdkn1a or p21) acting as the inhibitor of Cyclin $\mathrm{E} / \mathrm{Cdk} 2$ and, thus, promotes the cell cycle transition from $\mathrm{G} 1$ to $\mathrm{S}$ phase ${ }^{[25]}$.

The embryonic stem cell-specific cell cycle-regulating microRNAs (ESCC microRNAs) including miR-302b and miR-372 promote human somatic cell reprogramming by targeting TGF- $\beta$ receptor 2 and RhoC expression and inhibiting TGF- $\beta$-induced epithelial to mesenchymal transition (EMT)[37]. RhoC as a $\mathrm{G}$ protein would support the EMT by regulation of vascular endothelial growth factor (VEGF) and TGF- $\beta 1^{[38]}$. The microRNA cluster $302 / 367$ targets TGF- $\beta$ receptor 2 , enhancing the mesenchymal to epithelial transition (MET) which is a mandatory step for reprogramming of fibroblasts into iPS cells. On the other hand TGF- $\beta$ prevents MET ${ }^{[39]}$ by binding to TGF $\beta$ receptor 2 and promotes epithelial to mesenchymal transition (EMT) through phosphorylation of TGF $\beta$ receptor 1 that activates the Snail pathway ${ }^{[40]}$, where Snail acts as crucial transcription factor for activating $\mathrm{EMT}^{[41]}$.

It has been shown that miR-302 family members not only repress the cell cycle regulator Cyclin-dependent kinase inhibitor 1 (Cdkn1a / p21) but also the tumor suppressor retinoblastoma-like protein 2 $(\mathrm{Rbl2})^{[42]}$. miR-290 also silences Rbl2, which in turn transcriptionally 
represses the epigenetic modulator DNA-methyltransferase (DNMT). This leads to a significant hypomethylation of the genome and results in enhanced telomere recombination and increased telomere length ${ }^{[43]}$. Members of the miR-302 cluster directly target the methylDNA binding domain protein 2 (MBD2), an epigenetic suppressor that interferes with somatic reprogramming into iPS cells through direct binding to the Nanog promoter ${ }^{[4]}$. Other microRNAs like miR$130 / 301 / 721^{[29]}$ and miR-148, which target the homeobox transcription factor Meox2 (Mesenchyme Homeobox 2), act via p21 and p16 on the G1/S cell cycle checkpoint ${ }^{[45]}$. The miR-200 family (miR-141, miR-200a, miR-200b, miR-200c, miR-429) and miR-205 could enhance reprogramming of mouse embryonic fibroblasts, when a piggyBac transposon system expressing OSKM was used, triggering mesenchymal to epithelial transition (MET). These microRNAs repress the mesenchymal specific zinc finger transcription factors of Snail (Snai1), Slug (Snai2) and Zinc finger Ebox-binding homeobox pro-mesenchymal genes of Zeb1 and Zeb2. Thus, they enhance the initiation phase of OSKM reprogramming and act in synergy with some morphogenetic protein (BMP) pathways $^{[46,47]}$.

\section{Inhibition of microRNAs Against Pluripotency}

There are numerous microRNAs that act against pluripotency and repressing these microRNAs can support the induction or maintenance of pluripotency in cells (Figure 3). For example, miR145 directly targets the pluripotency factors Oct4, Sox2, and Klf4 and hinders hES cell self-renewal ${ }^{[48]}$. Inhibition of miR-145 promoted iPS reprogramming efficiency 2 times more than OSKM alone in human dermal skin fibroblasts, and resulted in elevated expression of pluripotency associated factors of Sox2, Klf4, c-Myc. Furthermore, miR-145 inhibition repressed let-7b, which would act as negative

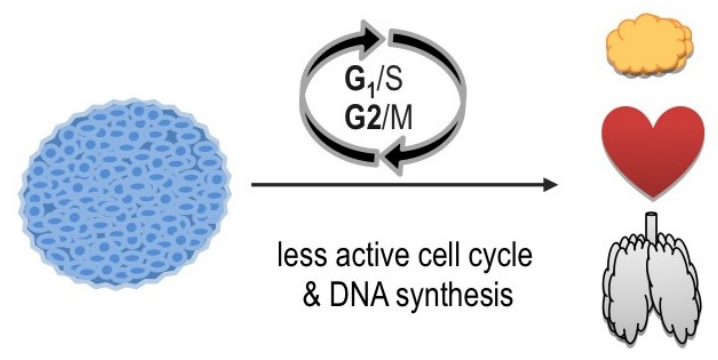

\section{MicroRNAs suppressing pluripotency and enhancing differentiation}
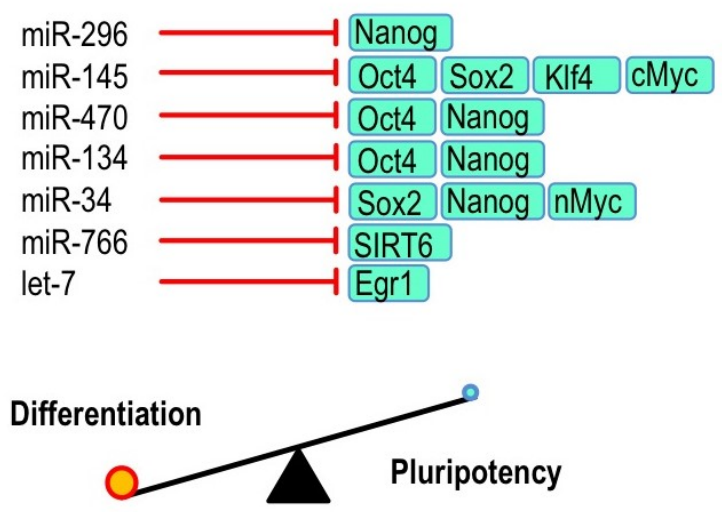

Figure 3: microRNAs that support differentiation

Overexpression of microRNAs targeting pluripotency factors leads to compromised stemness and self-renewal capacities and results in a cell state, which is more prone towards differentiation. regulator on iPS cell generation ${ }^{[49]}$. Furthermore, miR-132 and miR212 strongly inhibit reprogramming of MEFs into iPS cells by targeting important epigenetic regulators such as the histone acetyl transferase p300 and the H3K4 demethylase Jarid1a (KDM5a), but inhibition of miR-132 and miR-212 could enhance overall efficiency of iPS generation ${ }^{[50]}$.

It has been shown that let-7a, miR-21, and miR-29a are expressed higher in MEFs compared to mouse ES cells and inhibiting them by appropriate microRNA inhibitors (antagomirs) together with retroviruses expressing OSKM could yield a higher reprogramming efficiency specially by inhibiting miR-29a and miR-21. Interestingly, it was further shown that miR-29 represses the active DNA demethylation enzymes TET and TDG during somatic cell reprogramming ${ }^{[51]}$.

The reprogramming factor of c-Myc decreases the expression of the fibroblast specific microRNAs of miR-21 and miR-29a, explaining its enhancing effect in the reprogramming cocktail ${ }^{[52]}$. Inhibition of let-7 enhances efficiency and quality of human iPS cell reprogramming by de-repressing LIN-41 and subsequent downregulation of its direct target, Early Growth Response 1 (Egr1) as a pro-differentiation factor ${ }^{[53]}$. miR-34 represses Nanog, Sox 2 and $\mathrm{N}-\mathrm{Myc}$ by activating p53 which is a known barrier on the way of somatic reprogramming and $\mathrm{p} 21$ which in turn represses $\mathrm{p} 53^{[54]}$.

It was demonstrated that miR-199a-5p acts as a negative regulator during reprogramming of MEFs into iPS cells ${ }^{[50]}$ and targets the transcription activator, $\mathrm{Brg} 1^{[55]}$, which is an important and essential subunit of the SWI/SNF chromatin remodeling complex ${ }^{[56]}$. Interestingly, shRNA-mediated knockdown of Brg1 and Baf155, which are other components of this complex, significantly represses iPS cell formation from liver progenitor cells ${ }^{[57]}$. miR-199a-5p also targets E-cadherin, which is a strong pro-epithelial marker ${ }^{[58]}$ and inhibits iPS cell generation; however, transfection of miR-199a-5p inhibitor significantly enhanced lentiviral-based OSK reprogramming of MEFs into iPS cells demonstrated by more than two-fold increased Oct4-GFP positive colonies numbers compared to scramble microRNA transfected $\mathrm{MEFs}^{[50]}$. miR-199a-3p also inhibits reprogramming by targeting p21 activated kinase 4 (PAK4)[59], which is associated with stemness maintenance through supporting the expression of Oct4, Sox2, KLF4 and Nanog ${ }^{[60]}$. Unfortunately, this fact is often neglected that anti-miR- or antagomir sequences are not necessarily complementary to the opposite strand of intended microRNA since the two microRNAs are not necessarily aligned opposite to each other in the secondary structure of the pre-microRNA. This might explain, why it has been demonstrated that inhibition of both miR-199a-3p and miR-199a-5p by transfection of corresponding inhibitors, enhances reprogramming of MEFs into iPS cells ${ }^{[50,61]}$ since according to Mirbase.org, miR-199a-3p mimic has a seed sequence of "CAGUAGU" and the miR-199a-3p inhibitor has a seed sequence of "AACCAAT" while, miR-199a-5p mimic has a seed sequence of "CCAGUGU" and the miR-199a-5p inhibitor has a seed sequence of "AACAGGT", which are quite unrelated and exert their effect on gene regulation in different modes.

Another addressed issue during analysis of the effect of microRNAs on pluripotency is the type of microRNA that is studied. Normally, the endogenous microRNAs go through processing to give rise to pre-microRNAs and eventually yield the mature microRNA, but many studies have used the mature microRNA directly and some used pre-microRNA and the results are not necessarily the same where in the case of mir-199a-5p the transfection of the mature form significantly inhibited iPS generation but the pre-microRNA could not have the same effect. 
In conclusion, certain microRNAs present in somatic cells may block the process of mesenchymal to epithelial transition, or slow down proliferation by cell cycle-interference, or interfere with the induction of the pluripotency-related transcriptional network, and, thus, will affect the generation of iPS cells. Further research on these type of microRNAs is important because an impaired iPS generation setting may cause more genetic and epigenetic alterations. On the other hand, there are microRNAs, which enhance reprogramming by promoting the induction or maintenance of pluripotency, by promoting epigenetic remodeling, by promoting mesenchymal to epithelial transition, or by promoting an enhanced proliferation based on cell cycle acceleration. Finally, further studies on microRNAs along with inhibiting microRNAs in reprogramming may lead to a deeper understanding of the reprogramming mechanisms not only during iPS cell generation but also during direct transprogramming of cells from one lineage into derivatives of other lineages ${ }^{[62,63]}$; a process that will be supported by a microRNA-based modulation of the epigenetic remodeling or the cell cycle regulation as well.

\section{References}

1. Thomson JA, Itskovitz-Eldor J, Shapiro SS, Waknitz MA, Swiergiel JJ, Marshall VS, Jones JM. Embryonic stem cell lines derived from human blastocysts. Science. 1998;282(5391):1145-7.

2. Okita K, Ichisaka T, Yamanaka S. Generation of germlinecompetent induced pluripotent stem cells. Nature. 2007;448(7151):313-7.

3. Meissner A, Wernig M, Jaenisch R. Direct reprogramming of genetically unmodified fibroblasts into pluripotent stem cells. Nat Biotechnol. 2007;25(10):1177-81

4. Takahashi K, Tanabe K, Ohnuki M, Narita M, Ichisaka T, Tomoda $\mathrm{K}$, Yamanaka S. Induction of pluripotent stem cells from adult human fibroblasts by defined factors. Cell. 2007;131(5):861-72.

5. Yu J, Vodyanik MA, Smuga-Otto K, Antosiewicz-Bourget J, Frane JL, Tian S, Nie J, Jonsdottir GA, Ruotti V, Stewart R, Slukvin, II, Thomson JA. Induced Pluripotent Stem Cell Lines Derived from Human Somatic Cells. Science. 2007;318(5858):1917-20.

6. Gupta MK, Illich DJ, Gaarz A, Matzkies M, Nguemo F, Pfannkuche K, Liang H, Classen S, Reppel M, Schultze JL, Hescheler J, Saric T. Global transcriptional profiles of beating clusters derived from human induced pluripotent stem cells and embryonic stem cells are highly similar. BMC Dev Biol. 2010;10:98

7. Hu BY, Weick JP, Yu J, Ma LX, Zhang XQ, Thomson JA, Zhang SC. Neural differentiation of human induced pluripotent stem cells follows developmental principles but with variable potency. Proc Natl Acad Sci U S A. 2010;107(9):4335-40.

8. Song Z, Cai J, Liu Y, Zhao D, Yong J, Duo S, Song X, Guo Y, Zhao Y, Qin H, Yin X, Wu C, Che J, Lu S, Ding M, Deng H. Efficient generation of hepatocyte-like cells from human induced pluripotent stem cells. Cell Res. 2009;19(11):1233-42.

9. Liu H, Ye Z, Kim Y, Sharkis S, Jang YY. Generation of endodermderived human induced pluripotent stem cells from primary hepatocytes. Hepatology. 2010;51(5):1810-9.

10. Lister R, Pelizzola M, Kida YS, Hawkins RD, Nery JR, Hon G, Antosiewicz-Bourget J, O'Malley R, Castanon R, Klugman S, Downes M, Yu R, Stewart R, Ren B, Thomson JA, Evans RM, Ecker JR. Hotspots of aberrant epigenomic reprogramming in human induced pluripotent stem cells. Nature. 2011;471(7336):6873.

11. Ma H, Morey R, O'Neil RC, He Y, Daughtry B, Schultz MD, Hariharan M, Nery JR, Castanon R, Sabatini K, Thiagarajan RD, Tachibana M, Kang E, Tippner-Hedges R, Ahmed R, Gutierrez NM, Van Dyken C, Polat A, Sugawara A, Sparman M, Gokhale S, Amato P, Wolf DP, Ecker JR, Laurent LC, Mitalipov S. Abnormalities in human pluripotent cells due to reprogramming mechanisms. Nature. 2014;511(7508):177-83.

12. Choi J, Lee S, Mallard W, Clement K, Tagliazucchi GM, Lim H, Choi IY, Ferrari F, Tsankov AM, Pop R, Lee G, Rinn JL, Meissner A, Park PJ, Hochedlinger K. A comparison of genetically matched cell lines reveals the equivalence of human iPSCs and ESCs. Nat Biotechnol. 2015;33(11):1173-81.
13. Mallon BS, Hamilton RS, Kozhich OA, Johnson KR, Fann YC, Rao MS, Robey PG. Comparison of the molecular profiles of human embryonic and induced pluripotent stem cells of isogenic origin. Stem Cell Res. 2014;12(2):376-86.

14. Chin MH, Mason MJ, Xie W, Volinia S, Singer M, Peterson C, Ambartsumyan G, Aimiuwu O, Richter L, Zhang J, Khvorostov I, Ott V, Grunstein M, Lavon N, Benvenisty N, Croce CM, Clark AT, Baxter T, Pyle AD, Teitell MA, Pelegrini M, Plath K, Lowry WE. Induced pluripotent stem cells and embryonic stem cells are distinguished by gene expression signatures. Cell Stem Cell. 2009;5(1):111-23.

15. Razak SR, Ueno K, Takayama N, Nariai N, Nagasaki M, Saito R, Koso H, Lai CY, Murakami M, Tsuji K, Michiue T, Nakauchi H, Otsu M, Watanabe S. Profiling of microRNA in human and mouse ES and iPS cells reveals overlapping but distinct microRNA expression patterns. PLoS One. 2013;8(9):e73532.

16. Plews JR, Li J, Jones M, Moore HD, Mason C, Andrews PW, Na $\mathrm{J}$. Activation of pluripotency genes in human fibroblast cells by a novel mRNA based approach. PLoS One. 2010;5(12):e14397.

17. Warren L, Manos PD, Ahfeldt T, Loh YH, Li H, Lau F, Ebina W, Mandal PK, Smith ZD, Meissner A, Daley GQ, Brack AS, Collins JJ, Cowan C, Schlaeger TM, Rossi DJ. Highly efficient reprogramming to pluripotency and directed differentiation of human cells with synthetic modified mRNA. Cell Stem Cell. 2010;7(5):618-30.

18. Parisi S, Passaro F, Russo L, Musto A, Navarra A, Romano S, Petrosino G, Russo T. Lin28 is induced in primed embryonic stem cells and regulates let-7-independent events. FASEB J. 2017;31(3):1046-58.

19. Lin SL, Chang DC, Chang-Lin S, Lin $\mathrm{CH}$, Wu DT, Chen DT, Ying SY. Mir-302 reprograms human skin cancer cells into a pluripotent ES-cell-like state. RNA. 2008;14(10):2115-24.

20. Lin SL, Chang DC, Lin CH, Ying SY, Leu D, Wu DT. Regulation of somatic cell reprogramming through inducible mir-302 expression. Nucleic Acids Res. 2011;39(3):1054-65.

21. Miyoshi N, Ishii H, Nagano H, Haraguchi N, Dewi DL, Kano Y, Nishikawa S, Tanemura M, Mimori K, Tanaka F, Saito T, Nishimura J, Takemasa I, Mizushima T, Ikeda M, Yamamoto H, Sekimoto M, Doki Y, Mori M. Reprogramming of mouse and human cells to pluripotency using mature microRNAs. Cell Stem Cell. 2011;8(6):633-8.

22. Friedman RC, Farh KK, Burge CB, Bartel DP. Most mammalian mRNAs are conserved targets of microRNAs. Genome Res. 2009;19(1):92-105.

23. Lagos-Quintana M, Rauhut R, Yalcin A, Meyer J, Lendeckel W, Tuschl T. Identification of tissue-specific microRNAs from mouse. Curr Biol. 2002;12(9):735-9.

24. Sinkkonen L, Hugenschmidt T, Berninger P, Gaidatzis D, Mohn F, Artus-Revel CG, Zavolan M, Svoboda P, Filipowicz W. MicroRNAs control de novo DNA methylation through regulation of transcriptional repressors in mouse embryonic stem cells. Nat Struct Mol Biol. 2008;15(3):259-67.

25. Wang Y, Baskerville S, Shenoy A, Babiarz JE, Baehner L, Blelloch R. Embryonic stem cell-specific microRNAs regulate the G1-S transition and promote rapid proliferation. Nat Genet. 2008;40(12):1478-83.

26. Rosa A, Brivanlou AH. MicroRNAs in early vertebrate development. Cell Cycle. 2009;8(21):3513-20.

27. Ruiz S, Panopoulos AD, Montserrat N, Multon MC, Daury A, Rocher C, Spanakis E, Batchelder EM, Orsini C, Deleuze JF, Izpisua Belmonte JC. Generation of a drug-inducible reporter system to study cell reprogramming in human cells. J Biol Chem. 2012;287(48):40767-78.

28. Li Z, Yang CS, Nakashima K, Rana TM. Small RNA-mediated regulation of iPS cell generation. EMBO J. 2011;30(5):823-34.

29. Pfaff N, Fiedler J, Holzmann A, Schambach A, Moritz T, Cantz T, Thum $T$. miRNA screening reveals a new miRNA family stimulating iPS cell generation via regulation of Meox2. EMBO Rep. 2011;12(11):1153-9.

30. Sandhu SK, Fassan M, Volinia S, Lovat F, Balatti V, Pekarsky Y, Croce CM. B-cell malignancies in microRNA Emu-miR-17 92 transgenic mice. Proc Natl Acad Sci U S A. 2013;110(45):1820813. 
31. Rippe V, Dittberner L, Lorenz VN, Drieschner N, Nimzyk R, Sendt W, Junker K, Belge G, Bullerdiek J. The two stem cell microRNA gene clusters C19MC and miR-371-3 are activated by specific chromosomal rearrangements in a subgroup of thyroid adenomas. PLoS One. 2010;5(3):e9485.

32. Deng W, Cao X, Chen J, Zhang Z, Yu Q, Wang Y, Shao G, Zhou J, Gao X, Yu J, Xu X. MicroRNA Replacing Oncogenic Klf4 and cMyc for Generating iPS Cells via Cationized Pleurotus eryngii Polysaccharide-based Nanotransfection. ACS Appl Mater Interfaces. 2015;7(34):18957-66.

33. Judson RL, Babiarz JE, Venere M, Blelloch R. Embryonic stem cell-specific microRNAs promote induced pluripotency. Nat Biotechnol. 2009;27(5):459-61.

34. Hu S, Wilson KD, Ghosh Z, Han L, Wang Y, Lan F, Ransohoff KJ, Burridge P, Wu JC. MicroRNA-302 increases reprogramming efficiency via repression of NR2F2. Stem Cells. 2013;31(2):25968.

35. Anokye-Danso F, Trivedi CM, Juhr D, Gupta M, Cui Z, Tian Y, Zhang Y, Yang W, Gruber PJ, Epstein JA, Morrisey EE. Highly efficient miRNA-mediated reprogramming of mouse and human somatic cells to pluripotency. Cell Stem Cell. 2011;8(4):376-88.

36. Card DA, Hebbar PB, Li L, Trotter KW, Komatsu Y, Mishina Y, Archer TK. Oct4/Sox2-regulated miR-302 targets cyclin D1 in human embryonic stem cells. Mol Cell Biol. 2008;28(20):6426-38.

37. Subramanyam D, Lamouille S, Judson RL, Liu JY, Bucay N, Derynck R, Blelloch R. Multiple targets of miR-302 and miR-372 promote reprogramming of human fibroblasts to induced pluripotent stem cells. Nat Biotechnol. 2011;29(5):443-8.

38. Gou WF, Zhao Y, Lu H, Yang XF, Xiu YL, Zhao S, Liu JM, Zhu ZT, Sun HZ, Liu YP, Xu F, Takano Y, Zheng HC. The role of RhoC in epithelial-to-mesenchymal transition of ovarian carcinoma cells. BMC Cancer. 2014;14:477.

39. Liao B, Bao X, Liu L, Feng S, Zovoilis A, Liu W, Xue Y, Cai J, Guo X, Qin B, Zhang R, Wu J, Lai L, Teng M, Niu L, Zhang B, Esteban MA, Pei D. MicroRNA cluster 302-367 enhances somatic cell reprogramming by accelerating a mesenchymal-to-epithelial transition. J Biol Chem. 2011;286(19):17359-64.

40. Li R, Liang J, Ni S, Zhou T, Qing X, Li H, He W, Chen J, Li F, Zhuang Q, Qin B, Xu J, Li W, Yang J, Gan Y, Qin D, Feng S, Song H, Yang D, Zhang B, Zeng L, Lai L, Esteban MA, Pei D. A mesenchymal-to-epithelial transition initiates and is required for the nuclear reprogramming of mouse fibroblasts. Cell Stem Cell. 2010;7(1):51-63.

41. Zhou W, Wang Q, Xu Y, Jiang J, Guo J, Yu H, Wei W. RMP promotes epithelial-mesenchymal transition through NFkappaB/CSN2/Snail pathway in hepatocellular carcinoma. Oncotarget. 2017.

42. Tian Y, Zhang Y, Hurd L, Hannenhalli S, Liu F, Lu MM, Morrisey EE. Regulation of lung endoderm progenitor cell behavior by miR302/367. Development. 2011;138(7):1235-45.

43. Benetti R, Gonzalo S, Jaco I, Munoz P, Gonzalez S, Schoeftner S, Murchison E, Andl T, Chen T, Klatt P, Li E, Serrano M, Millar S, Hannon G, Blasco MA. A mammalian microRNA cluster controls DNA methylation and telomere recombination via Rbl2-dependent regulation of DNA methyltransferases. Nat Struct Mol Biol. 2008;15(3):268-79.

44. Lee MR, Prasain N, Chae HD, Kim YJ, Mantel C, Yoder MC, Broxmeyer HE. Epigenetic regulation of NANOG by miR-302 cluster-MBD2 completes induced pluripotent stem cell reprogramming. Stem Cells. 2013;31(4):666-81.

45. Douville JM, Cheung DY, Herbert KL, Moffatt T, Wigle JT. Mechanisms of MEOX1 and MEOX2 regulation of the cyclin dependent kinase inhibitors p21 and p16 in vascular endothelial cells. PLoS One. 2011;6(12):e29099.

46. Samavarchi-Tehrani P, Golipour A, David L, Sung HK, Beyer TA, Datti A, Woltjen K, Nagy A, Wrana JL. Functional genomics reveals a BMP-driven mesenchymal-to-epithelial transition in the initiation of somatic cell reprogramming. Cell Stem Cell. 2010;7(1):64-77.
47. Gregory PA, Bert AG, Paterson EL, Barry SC, Tsykin A, Farshid G, Vadas MA, Khew-Goodall Y, Goodall GJ. The miR-200 family and miR-205 regulate epithelial to mesenchymal transition by targeting ZEB1 and SIP1. Nat Cell Biol. 2008;10(5):593-601.

48. Xu N, Papagiannakopoulos T, Pan G, Thomson JA, Kosik KS MicroRNA-145 regulates OCT4, SOX2, and KLF4 and represses pluripotency in human embryonic stem cells. Cell. 2009;137(4):647-58.

49. Barta T, Peskova L, Collin J, Montaner D, Neganova I, Armstrong L, Lako M. Brief Report: Inhibition of miR-145 Enhances Reprogramming of Human Dermal Fibroblasts to Induced Pluripotent Stem Cells. Stem Cells. 2016;34(1):246-51.

50. Pfaff N, Liebhaber S, Mobus S, Beh-Pajooh A, Fiedler J, Pfanne A, Schambach A, Thum T, Cantz T, Moritz T. Inhibition of miRNA-212/132 improves the reprogramming of fibroblasts into induced pluripotent stem cells by de-repressing important epigenetic remodelling factors. Stem Cell Res. 2017;20:70-5.

51. Fraguas MS, Eggenschwiler R, Hoepfner J, Schiavinato JL, Haddad R, Oliveira LH, Araujo AG, Zago MA, Panepucci RA, Cantz T. MicroRNA-29 impairs the early phase of reprogramming process by targeting active DNA demethylation enzymes and Wnt signaling. Stem Cell Res. 2016;19:21-30.

52. Yang CS, Li Z, Rana TM. microRNAs modulate iPS cell generation. RNA. 2011;17(8):1451-60.

53. Worringer KA, Rand TA, Hayashi Y, Sami S, Takahashi K, Tanabe K, Narita M, Srivastava D, Yamanaka S. The let-7/LIN-41 pathway regulates reprogramming to human induced pluripotent stem cells by controlling expression of prodifferentiation genes. Cell Stem Cell. 2014;14(1):40-52.

54. Choi YJ, Lin CP, Ho JJ, He X, Okada N, Bu P, Zhong Y, Kim SY, Bennett MJ, Chen C, Ozturk A, Hicks GG, Hannon GJ, He L. miR-34 miRNAs provide a barrier for somatic cell reprogramming. Nat Cell Biol. 2011;13(11):1353-60.

55. Möbus S, Yang D, Yuan Q, Ludtke TH, Balakrishnan A, Sgodda M, Rani B, Kispert A, Arauzo-Bravo MJ, Vogel A, Manns MP, Ott M, Cantz T, Sharma AD. MicroRNA-199a-5p inhibition enhances the liver repopulation ability of human embryonic stem cell-derived hepatic cells. J Hepatol. 2015;62(1):101-10.

56. Ho L, Crabtree GR. Chromatin remodelling during development. Nature. 2010;463(7280):474-84.

57. Kleger A, Mahaddalkar PU, Katz SF, Lechel A, Joo JY, Loya K, Lin Q, Hartmann D, Liebau S, Kraus JM, Cantz T, Kestler HA, Zaehres H, Scholer H, Rudolph KL. Increased reprogramming capacity of mouse liver progenitor cells, compared with differentiated liver cells, requires the BAF complex. Gastroenterology. 2012;142(4):907-17.

58. Zhao X, He L, Li T, Lu Y, Miao Y, Liang S, Guo H, Bai M, Xie H, Luo G, Zhou L, Shen G, Guo C, Bai F, Sun S, Wu K, Nie Y, Fan D. SRF expedites metastasis and modulates the epithelial to mesenchymal transition by regulating miR-199a-5p expression in human gastric cancer. Cell Death Differ. 2014;21(12):1900-13.

59. Hou J, Lin L, Zhou W, Wang Z, Ding G, Dong Q, Qin L, Wu X, Zheng Y, Yang Y, Tian W, Zhang Q, Wang C, Zhang Q, Zhuang SM, Zheng L, Liang A, Tao W, Cao X. Identification of miRNomes in human liver and hepatocellular carcinoma reveals miR-199a/b-3p as therapeutic target for hepatocellular carcinoma. Cancer Cell. 2011;19(2):232-43.

60. Tyagi N, Marimuthu S, Bhardwaj A, Deshmukh SK, Srivastava SK, Singh AP, McClellan S, Carter JE, Singh S. p-21 activated kinase 4 (PAK4) maintains stem cell-like phenotypes in pancreatic cancer cells through activation of STAT3 signaling. Cancer Lett. 2016;370(2):260-7.

61. Wang J, He Q, Han C, Gu H, Jin L, Li Q, Mei Y, Wu M. p53facilitated miR-199a-3p regulates somatic cell reprogramming. Stem Cells. 2012;30(7):1405-13.

62. Eguchi T, Kuboki T. Cellular Reprogramming Using Defined Factors and MicroRNAs. Stem Cells Int. 2016;2016:7530942.

63. Pfaff N, Cantz T. From Skin to Blood: A New Member Joins the iClub. Cell Stem Cell. 2013;13(2):131-3. 


\begin{abstract}
Abbreviations
EMT: Epithelial to Mesenchymal Transition

ES cells: Embryonic Stem cells

iPS cells: Induced Pluripotent Stem cells

OSK: $\quad$ OCT4, SOX2, KLF4

OSKM: OCT4, SOX2, KLF4, c-MYC

OSNL: OCT4, SOX2, NANOG, LIN28

MEF: $\quad$ Mouse Embryonic Fibroblasts

MET: Mesenchymal to Epithelial Transition

mirPS: MicroRNA-Induced Pluripotent Stem cells
\end{abstract}

\title{
Potential Conflicts of Interests
}

None

\section{Acknowledgements}

The authors received funding from the German Research Foundation via the excellence cluster REBIRTH (DFG, EXC 62/3) and from the German Ministry for Education and Research (BMBF, 01GP1007C / 01GP1616C). Author Abbas Beh-Pajooh received a fellowship from Hannover Biomedical Research School.

\section{Corresponding Author}

Tobias Cantz, Translational Hepatology and Stem Cell Biology, Hannover Medical School, Carl-Neuberg- Str. 1, 30625 Hannover, Germany; E-Mail: cantz.tobias@mh-hannover.de 